\title{
Evaluating healthcare access in informal settlements using satellites and neural networks
}

1 Ishika Pal BTech Planning

Undergraduate student, Department of Civil Engineering, College of Engineering Pune, Pune, India (Orcid:0000-0001-5694-6231)

(corresponding author: ishikapal4688@gmail.com)
2 Arati Petkar BArch, MTech, PhD

Assistant Professor, Department of Civil Engineering, College of Engineering Pune, Pune, India (Orcid:0000-0003-2684-2049)
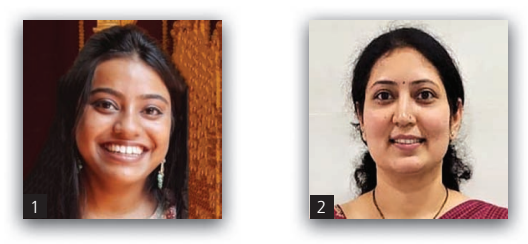

The right to affordable access to hospitals, clinics and dispensaries is one of the major priorities of government authorities. The constant migration towards cities and consequent growth of informal urban settlements make it imperative to consider the 'grid of influence' of such facilities. An attempt is made to understand this influence through satellite imagery and neural networking. Parameters such as distance from access roads and different types of informal settlements were analysed to understand their significance. These parameter models were then used as inputs for training a neural network in a case study area. Statistical plots helped understand the weight of the parameters, and accordingly, a spatial probability map was prepared. The results of the study could aid development officials in their various plans and proposals for their urban jurisdiction, helping increase accessibility to health facilities using modern predictive tools.

Keywords: artificial intelligence/artificial neural network/health/infrastructure planning/squatter settlements/town \& city planning

\section{Notation}

$f_{n} \quad$ number of facilities at the $n$ level of hierarchy

$w_{n} \quad$ weight calculated for facilities at the $n$ level of hierarchy

$X_{\text {in }} \quad$ input neurons

$x_{\text {in }} \quad$ input

$Y_{\text {in }} \quad$ weighted sum

$y_{\text {in }} \quad$ weighted inputs

$\mu \quad$ average value

\section{Introduction}

Public health is the practice of preventing disease and promoting good health within groups of people, from small communities to entire countries (APHA, 2014). Its activities provide conditions where people can be healthy and focus on entire populations, not individual patients or diseases (WHO, 2014). Such organisations deliver essential health services within a municipal jurisdiction. Today, increased occurrences of widespread diseases, high migration rate and slum proliferation have raised the demand for healthcare facilities. As per the census (Orgi, 2011), India's population has crossed 1210 million, with only $31.16 \%$ living in urban areas. Also, access to medical services for informal settlements is severely constricted due to inadequacy of the public health delivery system (MoHFW, 2013). This paper evaluates and analyses the spatial location of health facilities to ensure efficient response delivery.
Worldwide nearly 1 billion population live in informal settlements, which exposes them to increased health risks. Currently, health services for the informal sector in India are expensive. The informal sector contributes around 3-4\% to a city's gross domestic product (Mashal, 2010). It was estimated that $30-40 \%$ of the population in metros live in slums or slumlike habitation (Kumar et al., 2018). Ineffective outreach, weak referral system, social exclusion and lack of information and assistance restrict the access of the urban poor to affordable health services. In the recent outbreak of the pandemic, intense pressures on existing facilities led to the temporary construction of emergency hospitals throughout the country, highlighting the inadequacy of facilities in service. The lack of systematic planning for healthcare infrastructure in India has been sporadic and scanty, which resulted in poor primary healthcare (NITI Aayog, 2019). This research studies these lacunas and helps provide long-term solutions specifically for the informal sector within the hierarchical framework of the healthcare system in India (Figure 1). It attempts to bridge the chasm between development plans and resource allocation and on-ground healthcare requirements of the required beneficiaries.

The aim of this research is to understand and evaluate the healthcare infrastructure for informal settlements using artificial neural networking (ANN). The focus of this study was the spatial aspect of the health sector within a jurisdiction. It identified and located existing healthcare infrastructures to correlate them with the spatial distribution of informal settlements. The analysis uses ANN with a 
Smart Infrastructure and Construction

Volume 175 Issue 3
Evaluating healthcare access in informal settlements using satellites and neural

networks

Pal and Petkar

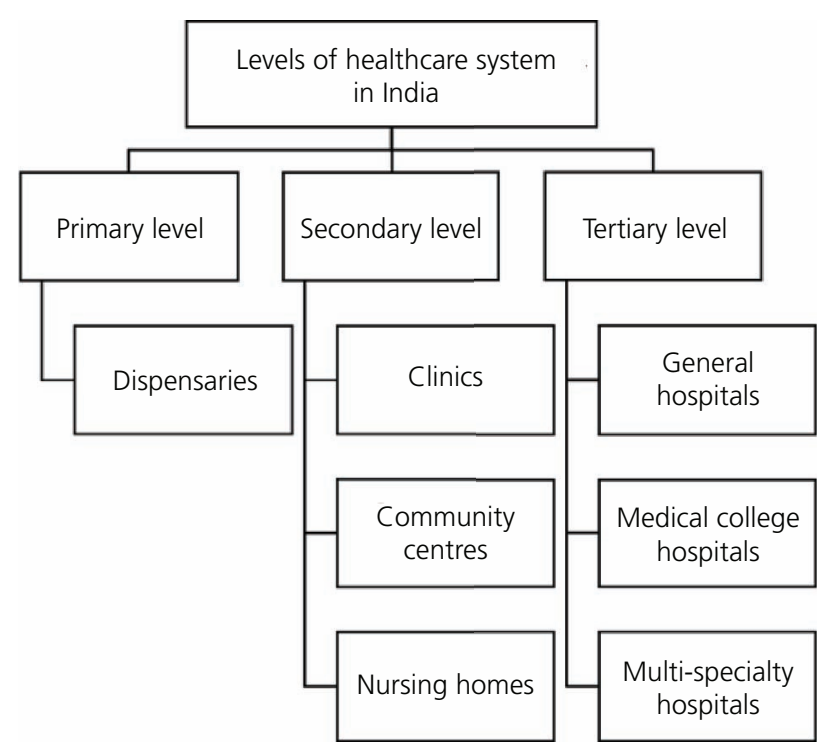

Figure 1. Hierarchy of healthcare systems in India

geographic information system (GIS) and the RStudio software program to assess the criterion of proximity between them. It follows up the model through validation and recommendations based on the predicted areas of need of the ANN model.

\subsection{Background on ANN}

A neural network $(\mathrm{NN})$ is a biological neuron, and its features serve as the basic unit of ANN. This modelling technique was created on the basis of a simplified mathematical model simulating the operation of a human brain. It consists of three layers as shown in Figure 2: the input layer (consists of all GIS data and categorical data), the hidden layer (computing layer of ANN within the software) and the output layer (in the form of graphs, maps and images).

In the ANN, $X_{\text {in }}$ forms the input neurons and are based on the input nodes provided by the user. $Y_{\text {in }}$ indicates a weighted sum, the weights of which are assigned automatically internally after numerous iterations within the network. Also, the sum of all weighted inputs $y_{\text {in }}$ indicates internal potential of a neuron of input $x_{\text {in. }}$. The iterations for $Y_{\text {in }}$ are carried out to converge the $X_{\text {in }}$ neurons into one single formula $y=f\left(Y_{\text {in }}\right)$ which shows the dependencies of each $X_{\text {in }}$. The weighted sum passed through the neuron activation function $y=f\left(Y_{\text {in }}\right)$ produces the final output. The bias (input) nodes act as a regression intercept. The connection lines represent the weight of one node into a node of the next layer. In terms of a regression model, these are the coefficients that were learned and multiplied by input value for that variable. ANN modelling has two phases. The first phase is the training phase, which trains the program. The outputs of this represent the target variable as the desired output. The second phase is the learning phase, which calibrates within the predictive area, where same parameters are applied. The network predicts event weights $(0-100 \%)$ based on learned weights. (Further details about ANN may be accessed from the book by Ciaburro and Venkateswara (2017)).

The NeuralNet package in $\mathrm{R}$ programming is built to train a multilayer perceptron. Like a regression, it approximates functional relationships between covariates and response variables as extensions of general linear models. The back-propagation algorithm further helps validate the results. The software programs used in this research - namely, GIS and R Programming language - are open and freely available. The codes utilised for this research, however, were hard-coded by the authors, with reference to a work on ANN in landslide analysis (2019) (AlThuwaynee, 2017).

In the initial research phase, the authors researched the use of other technologies such as convolutional NNs (CNNs) and recurrent $\mathrm{NNs}$ along with ANN. Although $\mathrm{CNN}$ is considered more powerful than ANN since its last layer is completely connected, ANN allows a higher fault tolerance and is best used when the dependencies of criteria used as input are unknown. This makes ANN more favourable for any socio-economically based planning problem, since dependencies can be derived and even added later into the NN.

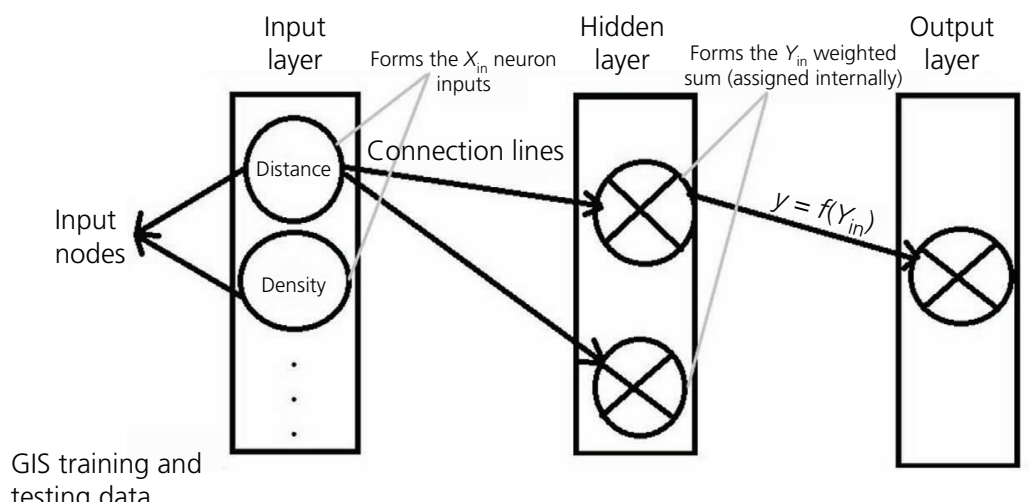

Figure 2. ANN diagrammatic representation 


\section{Literature review}

To understand the healthcare dynamics of a region, it must be first understood how it relates to those living in the lowest social stratum of society: the informal settlement arising from the informal sector. This sector is defined as a unit that consists of workers involved in non-taxed businesses offering low to no wages to labourers (OECD, 2003). According to the Rockefeller Foundation (2013), the informal sector is subject to restriction on access to affordable healthcare. It proposed policymakers to issue policies that highlight their health priorities. There is considerable potential for the government to build on strengthening the equity of access. An integrated model encompassing primary, secondary and tertiary care would be of greater benefit and cost effective (Rao et al., 2011). The lack of indepth study of sociocultural factors, knowledge and belief on modern healthcare systems and economic and other barriers to access proved to be the main reason behind the lack of research studies on the accessibility factor of healthcare services. Brown et al. (2010) analysed that for a country such as India, there was no consensus about whether regional or national databases should be combined. Thus, it was inferred that positioning of healthcare facilities plays an important role in equitable service provision. However, healthcare infrastructures may also be thought of as 'living labs' - dynamic to surrounding environments (Hesseldal and Kayser, 2016). Gumber (2002) suggested the spatial distribution of healthcare facilities to be based on education, income and occupation criteria of visiting patients. These criteria, which form the socio-economic basis of a locality, could be the next step in bridging inequality. As the population become diverse, healthcare infrastructure must become more pervasive socially through cellular automata and CNN models (Aarthi and Gnanappazham, 2019; Revelu, 2020). According to Noack et al. (2014), ANN offers a modelling approach that helps relate a depending variable and other factors for any geographic problem. It serves as an efficient tool for data validation through regression and scatter plots (Škrabánek and Martínková, 2021).

\section{Methodology}

This research work was carried out in four phases. The first phase determines the cause of issues that the healthcare sector faces when it comes to informal settlements. It is based on a review of pre-existing studies, evaluation models, literature and discussion with experts. The second phase physically maps the spatial locations of these facilities and analyses them digitally to understand their trend. This phase also maps the study area into different grid zones to analyse the data into density grids. The next phase utilises this density grid to assign weights to facilities depending on their hierarchy - primary (dispensaries), secondary (clinics and nursing homes) and tertiary (general hospitals and multi-specialty hospitals). This is then integrated with the ANN model using systemic biases. As the output, it maps a raster probability cloud map that depicts the feasibility of the predictive model based on the data entered. The last phase validates the ANN model using success and prediction rates. This forms the base for a credible and accurate prediction, which is further analysed using a sample scenario. The scenario built shows how the map changes if further criteria were to be added. The model is GIS and ANN based, built in RStudio and predicts the future locations of facilities based on current data, accessibility from existing informal settlements and regional topography.

\section{Case study area: Pune, India}

Pune is the seventh largest city in India and the second largest in the state of Maharashtra. The Pune Municipal Corporation (PMC) jurisdiction is $243.84 \mathrm{~km}^{2}$, housing 2.54 million populace within 144 wards. Referred to as the 'Detroit of India', the city has a long-standing urban tradition: as a historical centre of precolonial urbanism, as an important military centre during British rule, as a rapidly growing contemporary industrial centre and today as a growing metropolis (WSA and IL\&FS, 2008). Pune, also known as the 'Oxford of India', houses six universities with about 600 functional higher-education centres catering to an estimated 0.5 million student population.

Area-wise, Pune constitutes approximately $20 \%$ of the total Pune Metropolitan Region. Since 1951, the area has doubled from 125.75 to $243.84 \mathrm{~km}^{2}$. An average population density as per the census (Orgi, 2011) for PMC is 5600 persons $/ \mathrm{km}^{2}$. Since 1991, the growth of slums has increased rapidly in Pune (as shown in Figure 3). Despite this economic prowess, in the healthcare infrastructure, Pune was the city with the highest number of cases (of coronavirus disease (Covid) 2019), even though the city had high-quality healthcare facilities in place.

\section{Survey analysis}

According to the surveys conducted by authors, it was observed that there were over 195 healthcare facilities located within the PMC jurisdiction in Pune. Of these, 80 were multi-specialty hospitals, 105 were clinics ranging from skin specialist to family doctors and only ten were centralised or local dispensaries.

Figure 4 shows the spatial distribution of healthcare facilities in Pune. The healthcare facilities surveyed were categorised into three levels primary level, secondary level and tertiary level. Each of these levels increases in service capacity and was observed to have a bigger sphere of influence as the level moves from primary to tertiary. Although numerous types of facilities may be included in each of the

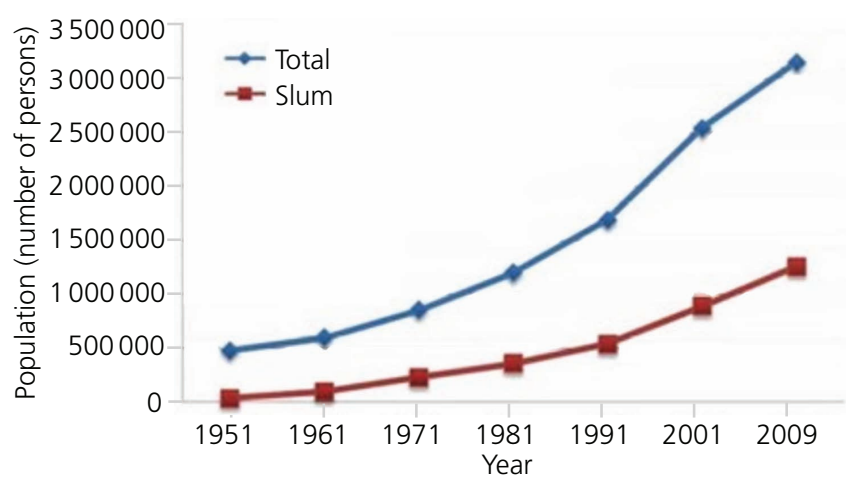

Figure 3. Growth rate of slums in Pune (PMC, 2015) 
Evaluating healthcare access in informal settlements using satellites and neural networks

Pal and Petkar

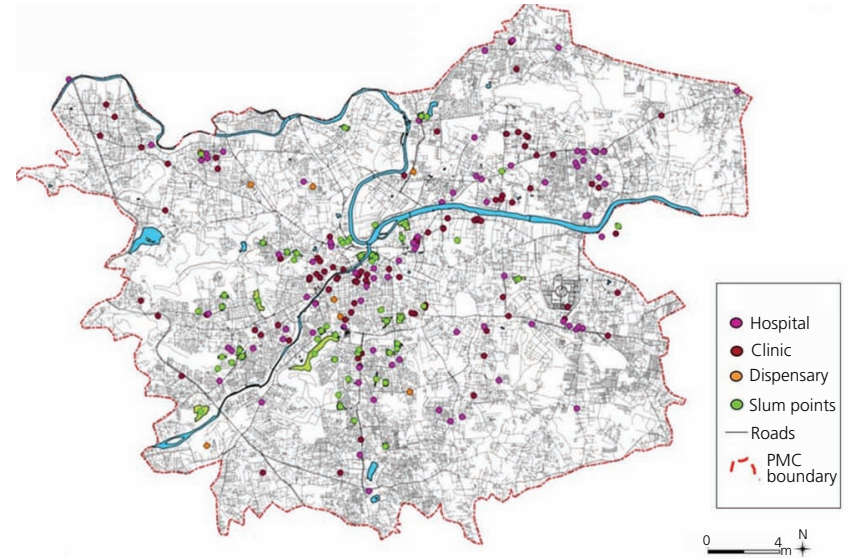

Figure 4. Healthcare facility distribution in Pune

levels as reviewed from Ministry of Health documents, this study is limited to the ones in the study area.

The 195 facilities surveyed comprise $89 \%$ of all the healthcare facilities in Pune under PMC. Of these, the maximum number was observed to be of secondary level (i.e. clinics and nursing homes), with $51 \%$. This was followed by the tertiary level (hospitals: 44\%) and then dispensaries, with only 5\%. A special type of facility included in the 'clinic' category consisted of those that were extremely local such that they were operated from homes and could not be categorised in any formal level.

\subsection{Analysis of tertiary-level facilities}

It is observed in Figure 5 that hospitals were not distributed but rather clustered in certain locations along main roads. This was due to the emergency vehicle services. Most of the older wards in Pune had at least one major city-level hospital. The majority of these hospitals were privately owned $(48 \%)$, followed by government or public owned $(42 \%)$. Of the distribution that was categorised as 'other', $10 \%$ were

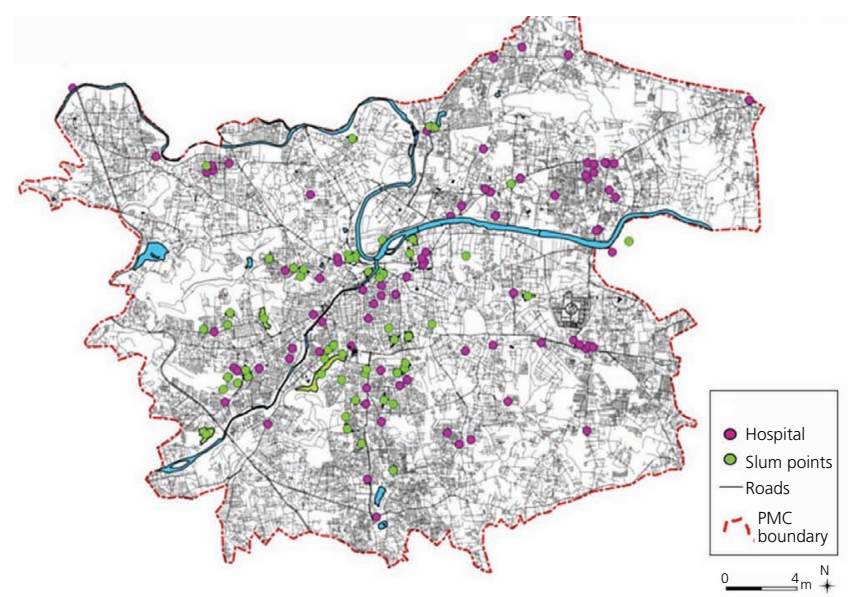

Figure 5. Distribution of hospitals in Pune joint ownerships. Ninety per cent of the hospitals were equipped with an emergency ward and an emergency vehicle. A majority of the tertiary facilities that were located in the older wards of Pune were in proximity to the access roads and comprised $90 \%$ of the total hospitals, and $6 \%$ were located within a $200-600 \mathrm{~m}$ range. The $4 \%$ that were located more than $600 \mathrm{~m}$ away from the access roads were all situated in the newer peripheral wards of the city. The maximum distance observed was $850 \mathrm{~m}$ away. According to the Urban and Regional Development Plans and Formulation Implementation (URDPFI) guidelines (Ministry of Urban Development, 2015), this figure should be $500 \mathrm{~m}$ in urban areas. This figure of threshold distance has been utilised as an influencing parameter.

Majority of the facilities were $800-2000 \mathrm{~m}$ away from the nearest informal settlements $(43 \%)$, while $28 \%$ were located even farther away. Thus, it was proven that informal settlements often fell beyond the grid of influence of major healthcare facilities. Although the shortest distance was $100 \mathrm{~m}$, this was observed only in the core wards of the city. For some beneficiaries, since the nearest facility was a hospital, they directly visited those 'sensitive' facilities and, in times of the pandemic, often contracted the virus. This further translated into the increase in the number of cases for a facility, creating a vicious cycle of burdened facilities and high number of cases.

\subsection{Analysis of secondary-level facilities}

It was shown by the analysis of the clinics in Pune that a major portion carried out specialised treatments such as skin treatment and hair treatment. Although clinics were well spread out, some had the capability of a dispensary but were functioning as a ward clinic. Figure 6 maps the spatial distribution of these secondary-level facilities. Over 100 secondary-level facilities were surveyed, and 56\% of these were located in the older core areas of the city. On close examination, it was observed that there were many unserved areas in the city, which probably contributed to the high number of (Covid) cases in the city. The maximum number of clinics belonged to the multi-specialty type, which essentially functioned as a tertiary-level

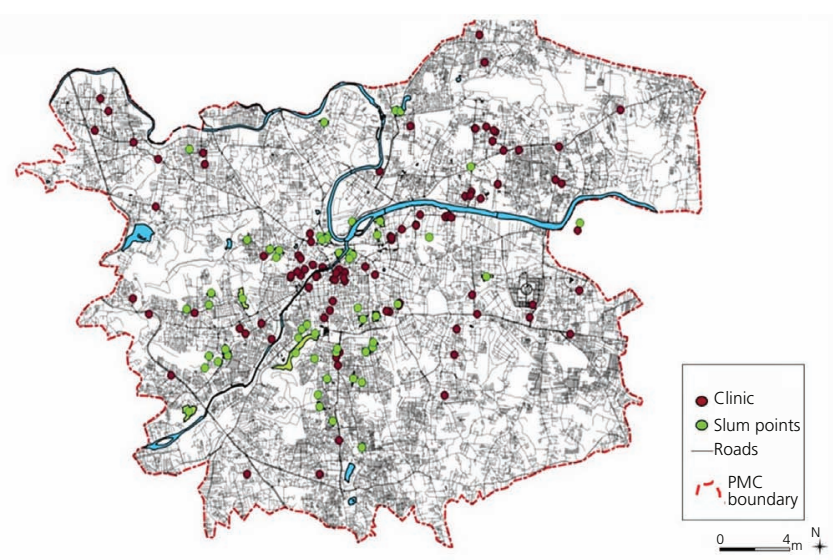

Figure 6. Distribution of clinics in Pune 
Smart Infrastructure and Construction

Volume 175 Issue 3
Evaluating healthcare access in informal

settlements using satellites and neural

networks

Pal and Petkar facility but did not have the equipment to be classified as a facility of that level. The next major category was the single-specialty clinics $(=30 \%)$. A significant detail observed during the survey was the high number of 'eye-specialty' clinics in the city. The reason was found to be the high number of senior citizens, information technology and educational professionals that reside in the city. Of the clinics and nursing homes surveyed, $57 \%$ were located in the $200-800 \mathrm{~m}$ bracket range. However, similar to the tertiary-level facilities, they were located in the core area. Almost $25 \%$ of the facilities were located more than $800 \mathrm{~m}$ away from the nearest informal settlement. The maximum distance observed was $1500 \mathrm{~m}$, as this informal settlement was located in the outermost periphery of the PMC jurisdiction. An interesting phenomenon observed was that beyond the PMC, the next cluster of healthcare facilities was located in the heart of the Pimpri Chinchwad municipal jurisdiction, more than $5 \mathrm{~km}$ away from the outermost informal settlement in the PMC boundary. This created a zone devoid of any healthcare facility. Thus, the residents in this zone had to travel more than $2 \mathrm{~km}$ to the nearest clinic or hospital. This aspect was further explored in detail during the generation of a scenario after the ANN model was run.

\subsection{Analysis of primary-level facilities}

Upon survey, it was observed that only ten central dispensaries were located in Pune. The maximum distance between the dispensaries and the nearest informal settlement was observed to be $1867 \mathrm{~m}$, while the shortest was observed to be $400 \mathrm{~m}$. Figure 7 shows the geographical location of the ten existing dispensaries in Pune that form the primary level of healthcare facilities. Fifty per cent of these facilities were located in the older wards of the city. In Pune, almost $80 \%$ of the dispensaries were found to be dedicated to dispensing medical equipment and medicines to the entire city, while the remaining ones acted as local neighborhood pharmacies with in-house doctors providing basic general medical advice. It was inferred that the lack of medical supplies in Pune during the Covid pandemic was probably due to the limited number of dispensaries and stock houses. This also made it essential to understand the importance of dispensaries in urban settlements, particularly when healthcare service is expensive. The main
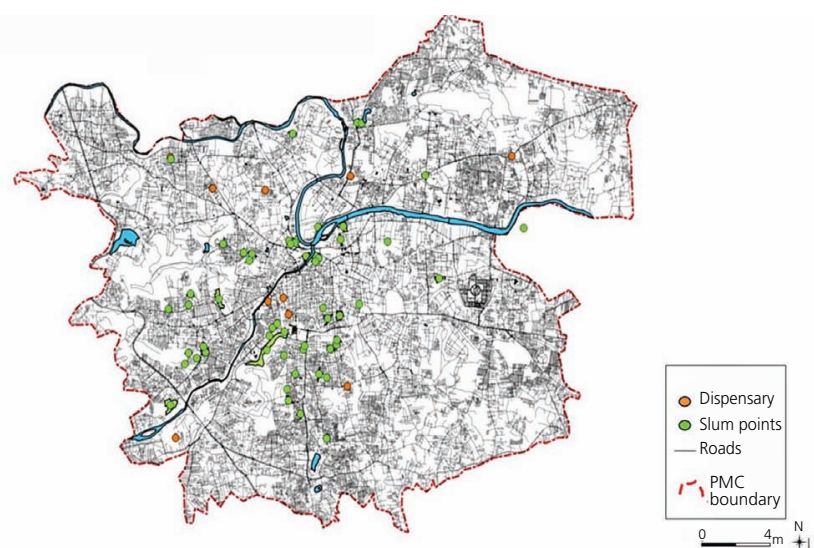

Figure 7. Distribution of dispensaries in Pune observation from the surveys was that despite the numerous healthcare facilities available, most of them were limited only to certain locations in the city. Few of these facilities were located in close proximity to informal settlements. The general clinics were limited, whereas most of the city hospitals were general specialty, thus leading to crowding of patients in the hospitals. This was found to be the major reason for building emergency hospitals during the pandemic of 2020. Clustered facilities, lopsided functionality and low frequency of facilities near informal settlements were major analysis points of the survey.

\section{Modelling}

Post collection of data from surveys, the next step was correlating this work digitally through GIS and ANN in the RStudio software program. For this purpose, it was necessary to formulate a density map of the study area. This map was crucial in converting the categorical data into numeric form, which was then converted to binary in the ANN training and learning data. For this, the threshold influence of every level of facility was calculated. According to the URDPFI guidelines in India, one hospital is meant to cater to a population of 250000 persons. And the census (Orgi, 2011), shows the population density of Pune is $5600 / \mathrm{km}^{2}$. This meant that 5600 persons occupied $1 \mathrm{~km}^{2}$, so 250000 persons should occupy approximately $45 \mathrm{~km}^{2}$. Considering the growth in population over the decade, this figure was rounded up to $49 \mathrm{~km}^{2}(7 \times 7 \mathrm{~km})$. Thus, the hospital threshold grid size was decided to be $7 \times 7 \mathrm{~km}$. Similarly, considering the relevant statistics for clinics $(1$ clinic $=100000$ persons), the grid was calculated to be $4 \times 4 \mathrm{~km}$, and for dispensaries, it was $3 \times 3 \mathrm{~km}$.

However, only the secondary level was used as the relevant grid of influence in creating the ANN model. This was because the smallest grid size did not effectively cover the influence of hospitals and the largest one posed a possibility of skewing the results given its area as opposed to that of dispensaries, which are the primary level. The density map was grid based and was also weighted. The weights were assigned based on the grid size of the facility and the total number of facilities (of the same type) (Table 1). The significance of weights in the density map was to calibrate the grid of influence of all level facilities recorded to a standard level so that they could be located together on the same grid.

1. $w_{\mathrm{t}}=\frac{\sum f_{\mathrm{t}}}{49}$

Table 1. Weighted overlay of healthcare facilities

\begin{tabular}{|llc|} 
Number & \multicolumn{1}{c}{ Type of facility } & $\begin{array}{c}\text { Weight } \\
\text { assigned }\end{array}$ \\
\hline 1 & Tertiary - hospitals & 0.62 \\
2 & Secondary - clinics and nursing & 0.25 \\
3 & homes & 0.13 \\
& Primary - dispensaries & 1.00 \\
\hline
\end{tabular}


where $\Sigma f_{\mathrm{t}}$ represents the total number of tertiary facilities.

$$
\text { 2. } w_{\mathrm{s}}=\frac{\sum f_{\mathrm{s}}}{16}
$$

where $\Sigma f_{\mathrm{s}}$ represents the total number of secondary facilities.

3. $w_{\mathrm{p}}=\frac{\sum f_{\mathrm{p}}}{9}$

where $\Sigma f_{\mathrm{p}}$ represents the total number of primary facilities.

The first terms of Equations 1-3 account for the weights of tertiary, secondary and primary facilities, respectively. The summation terms indicate the number of that type of facility in the grids shown in Figure 8.

In Figure 8, it was observed that the distribution was skewed towards the core areas, while the more recent wards were dependent on facilities in the core areas. Thus, with the help of grid analysis and weighted overlay, the results were fed in the ANN model. In this, the relation between the location of healthcare facilities and their distance to existing locations of informal settlements was analysed. This study correlated the 195 mapped facilities with the 54 informal settlements located in the city.

\subsection{ANN model}

After converting the density map into binary data, a distance threshold value was input in the model as the main condition parameter. This threshold distance for all the calibrated facilities was decided to be $500 \mathrm{~m}$, which was calculated by taking the mean of the proximity of the hierarchical facilities to informal settlements using the weights calibrated in the previous section.

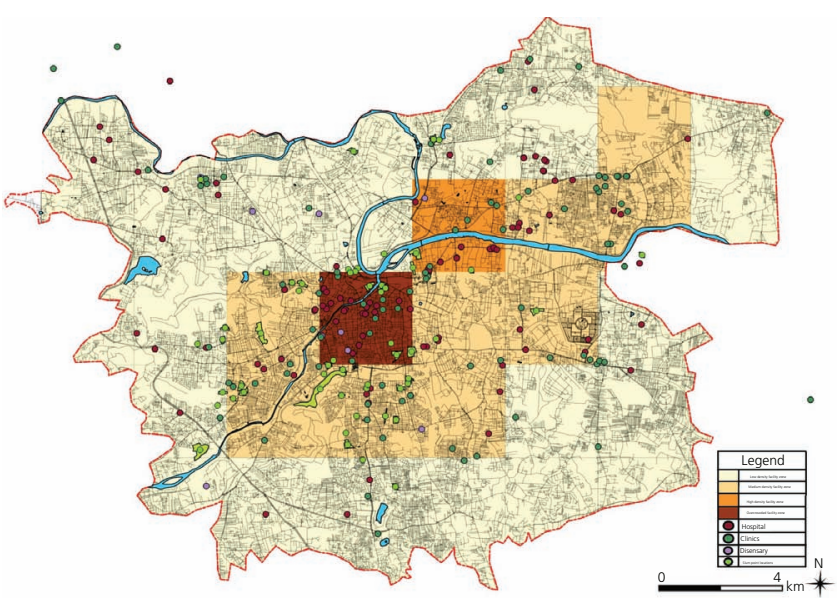

Figure 8. Existing density of healthcare facilities in a clinic grid
4. threshold distance $=\frac{\left[\left(0.62 \times \mu_{\mathrm{t}}\right)+\left(0.25 \times \mu_{\mathrm{s}}\right)+\left(0.13 \times \mu_{\mathrm{p}}\right)\right]}{3}$

where $\mu$ represents the mean proximity of a facility (primary/ secondary/tertiary) to an informal settlement.

These averaged distances were then calibrated using the weight calculation per level of facility similar to the previous section, and the final number was rounded up to the next hundred integer distance. In this case, the final threshold distance was calculated to be $430 \mathrm{~m}$, which was rounded up to $500 \mathrm{~m}$ for ease of calculation in the ANN model. Table 2 details the criteria used in the ANN model and their significance through the process.

The next step was to train and test all 7508 data points with respect to the threshold distance. Once the data were recorded and digitised, they were fed into the RStudio software program. This simulation process was broken into two phases - the learning phase and the testing phase. The first phase had three layers input, hidden and output layers. This phase made use of the training data, which were $60 \%$ of the total data points (4505), while the second phase made use of the testing data (the remaining $40 \%=3003$ data points). This was where the predictive simulation was carried out and a forecasted model was prepared.

The digital geographic data, which were computed using the GIS software, comprised the boundary of the study area, spatial locations of $89 \%$ of all healthcare facilities in Pune and 54 informal settlements from which distance calculations and grid analysis was carried out. Through the Las Palmas QGis 2.18 software, tools such as the distance calculator and grid analysis tool were applied to achieve the results. These results were then formulated in a tabular format in the RStudio software where categorical data were converted into binary $(0,1)$ data. The 'good' data where the proximity distance was

Table 2. Criteria used to create the ANN model

\begin{tabular}{|c|c|c|c|}
\hline Criterion & Data & $\begin{array}{l}\text { Reason for } \\
\text { using data }\end{array}$ & $\begin{array}{c}\text { Significance of } \\
\text { data }\end{array}$ \\
\hline Proximity & $\begin{array}{l}\text { Distance of the } \\
\text { healthcare facility } \\
\text { to the informal } \\
\text { settlement }\end{array}$ & $\begin{array}{l}\text { To assess data } \\
\text { using the } \\
\text { threshold } \\
\text { distance }\end{array}$ & $\begin{array}{l}\text { Forms the } \\
\text { condition } \\
\text { factor in the } \\
\text { program code }\end{array}$ \\
\hline $\begin{array}{l}\text { Nature of } \\
\text { informal } \\
\text { settlement }\end{array}$ & $\begin{array}{l}\text { Value attribute of } \\
\text { the mapped } \\
\text { informal settlement } \\
\text { (notified/non- } \\
\text { notified } \\
\text { settlements) }\end{array}$ & $\begin{array}{l}\text { To understand } \\
\text { the change } \\
\text { in bias in } \\
\text { ANN }\end{array}$ & $\begin{array}{l}\text { Converted to } \\
\text { binary and acts } \\
\text { as input }\end{array}$ \\
\hline Density & $\begin{array}{l}\text { Calibrated grid } \\
\text { density data of all } \\
\text { facilities }\end{array}$ & $\begin{array}{l}\text { To use the } \\
\text { data in the } \\
\text { predictive } \\
\text { stage of } \\
\text { ANN }\end{array}$ & $\begin{array}{l}\text { Translates into } \\
\text { the probability } \\
\text { cloud of the } \\
\text { model } \\
\text { developed }\end{array}$ \\
\hline
\end{tabular}


Smart Infrastructure and Construction

Volume 175 Issue 3
Evaluating healthcare access in informal settlements using satellites and neural

networks

Pal and Petkar below $500 \mathrm{~m}$ were classified as 0 , as they did not require assessment, being within the desired range. The 'bad' data were classified as 1 and had values greater than $500 \mathrm{~m}$. Once the data were assessed with a bias input from within the system, it was examined - whether the entered data could prove useful for predictive simulations. If the data converged, they were considered fit for prediction. If they did not, the entire code had to be run again while changing certain parameters such as the percentage of training to testing data. For the final model, the percentage share was $60 \%$ training data and $40 \%$ testing data. The last step of this process printed out the predicted data into a raster file, converting the input binary data back into categorical type (shown as a probability range map in Figure 13). For this study, 2.68 million scenarios were run in the simulation and the best scenario was converted as the final ANN model.

Figure 9 is the pictorial representation of the ANN model through R. The arrow lines are 'connection lines' that represent the bias in every step, while the external blue nodes are the general weights applied through the back-propagation algorithm. These inputs then passed through the hidden layer processing. Each of the nodes represents a neuron (similar to human brain neurons) that contains data as input from the 'distance' criterion. These input neurons are weighed (figures in black), pass through the hidden layer and are weighed by the backpropagation algorithm (figures in blue). This weighted analysis converges in the output layer and presents a final bias.
Figure 10 plots the function of the NN plot. It is the diagrammatic representation of Figure 9. The letters I1 and I2 represent the input neurons (i.e. the 'distance' criterion); $\mathrm{H} 1, \mathrm{H} 2$ and $\mathrm{H} 3$ are the hidden layer neurons within the network; B1 and B2 represent the neurons that assign biases through the back-propagation algorithm; and $\mathrm{O} 1$ is the final output neuron. The thickness of the connection lines indicates the bias assigned in a particular scenario by the NN package. This plot provides an insight into the significance of each parameter in comparison with that of others. It was inferred from Figure 10 that the distance from a non-notified informal settlement was more significant. This meant that healthcare facilities were located farther for non-notified slums and there was a lack of facilities in newer developed wards

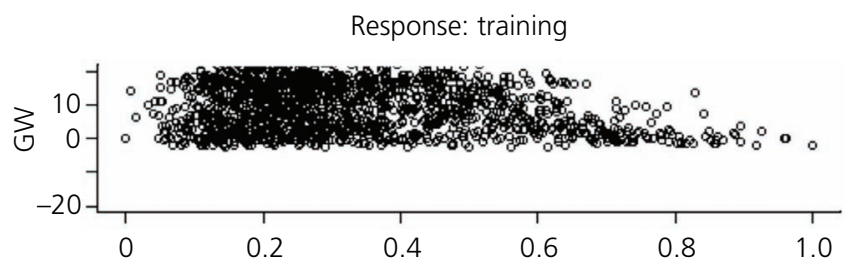

Figure 11. Generalised weight plot of distance to informal settlements

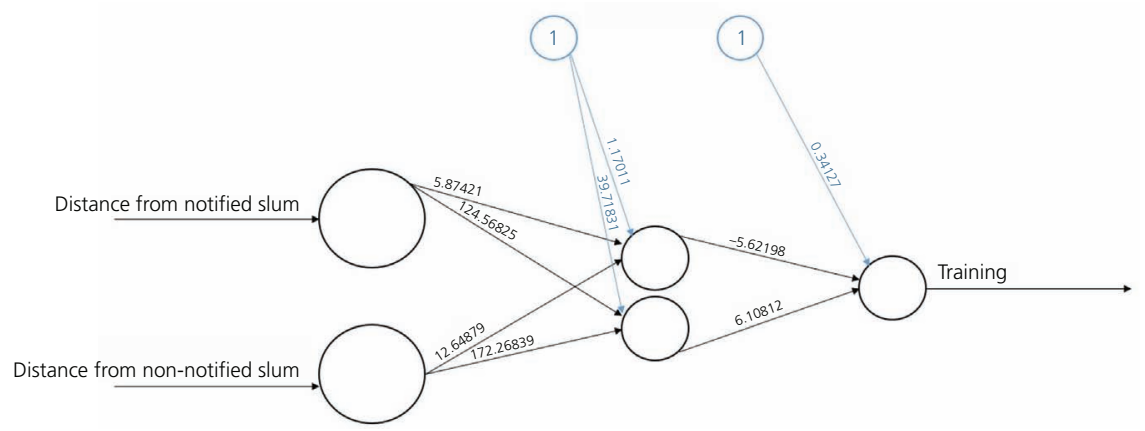

Figure 9. NeuralNet computing evaluation plot

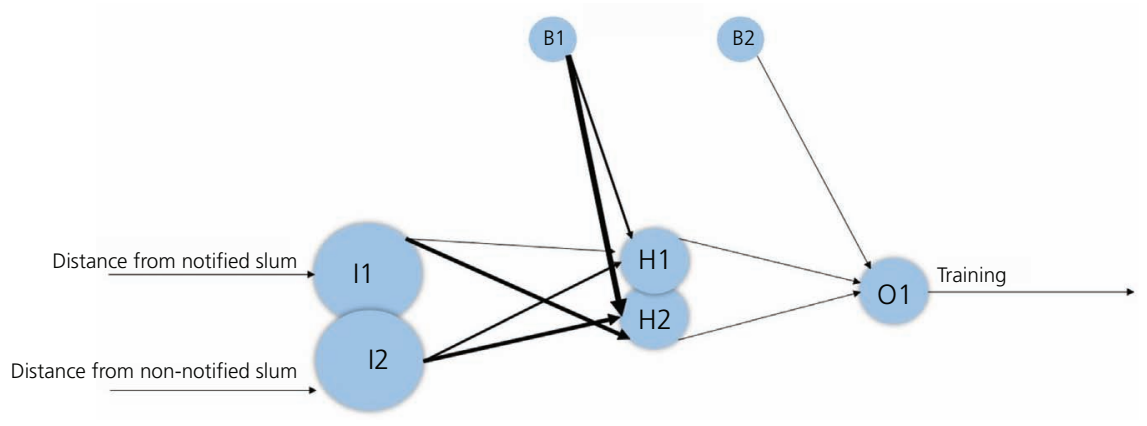

Figure 10. NeuralNet function plot 
of the city since most of the non-notified informal settlements were located beyond the downtown area of PMC.

Figure 11 denotes the weighted distribution of input data. On the $Y$-axis, GW represents the 'generalised weights', while the $X$-axis plots the distance recorded digitally on the GIS software. The ANN process allots weights to these numeric figures with the bias networked in Figure 9. According to Noack et al. (2014), it is preferable to have the mean of such a distribution near $0.5 \pm 0.2$. For this data set, it was 0.43 (which was also the original threshold distance calculated earlier). This proved the ANN predictive model to be true and fit for forecasting and depicted the existing trend of the data input.

Figure 12 shows a pairwise correlation of the distance ('ANN-W') and type of informal settlements ('V2'). The line graph along V2 shows whether the training data (on top) connect to the testing data (in the bottom) positively - that is, a negative slope or negatively with a positive slope. This degree of (positive/ negative) covariation is shown numerically in the top right box.

The covariation factor between the distance and type of informal settlements was found to be 0.8 . The three red stars indicate high covariance. It could be understood that although achieving perfect covariance $(=1)$ is possible only in theoretical conditions, the incidence of highly clustered facilities near few informal settlements could be the exceptions that limited the covariance to 0.8 . Also, it is not advisable to have a covariance higher than 0.9 (Ciaburro and Venkateswara, 2017), as that would rule out the implication of any other factor affecting the spatial locations of the facilities. Lower covariance, on the other hand, would mean that the criteria considered for analysis do not relate, which would not lead to conclusive predictions.

In the point distribution of Figure 11, it was observed that the points were evenly distributed from 0.23 to 1.00 , which meant that the data set was a good sample size for forecasting. The

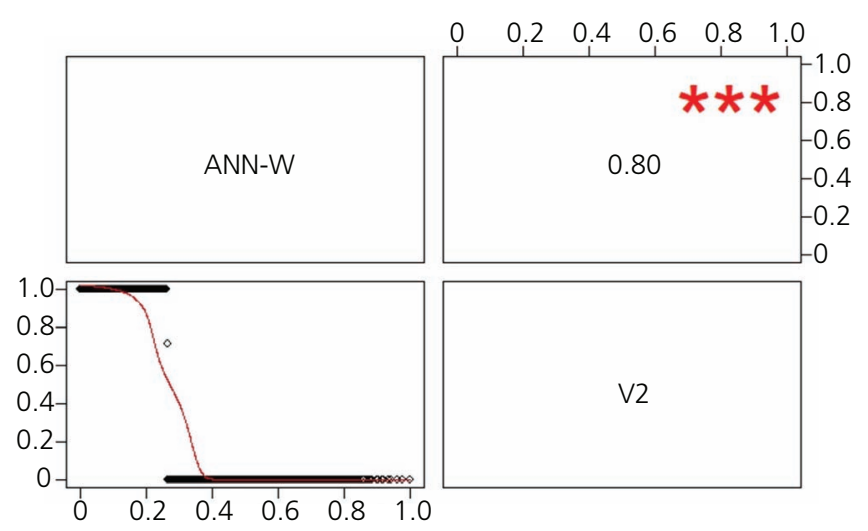

Figure 12. Pairwise correlation between healthcare facilities and informal settlements

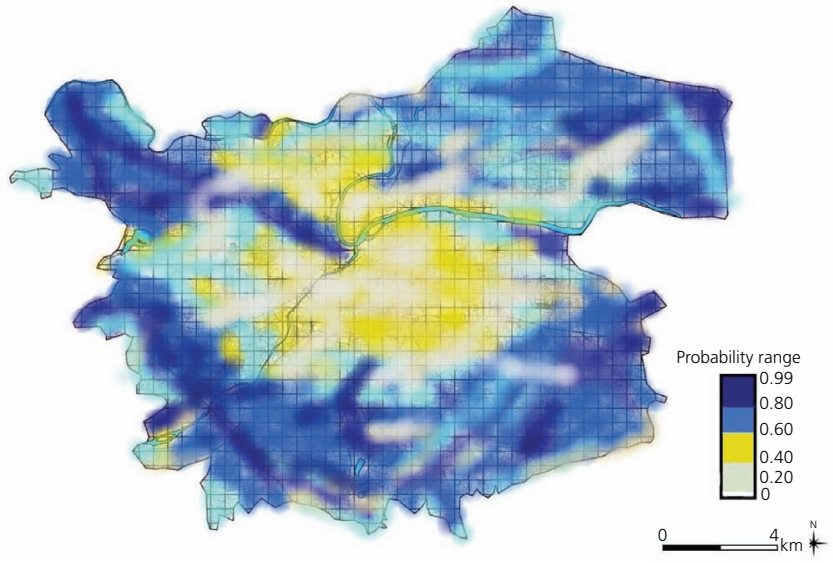

Figure 13. Phase 2 of ANN model - prediction map of PMC

overall error in the simulation model was $4.202(0.04 \%)$, which indicated four in every 1000 data points to be inaccurately mapped. With the learning phase having been completed along with its analysis, the next stage was the testing phase, where a predictive map was created based on the data input and $\mathrm{NN}$ simulation.

\section{Data validation}

After the raster map had been generated, it was fed back into GIS to divide the study area into grids, based on the primary level of facility - that is, the dispensaries. Every grid on the map suggested a certain degree of probability indicative of the demand and need of a facility. Apart from this, the predictive map was created in such a way that it suggested the overall demand of a healthcare facility without specifying the nature of the facility. This was because the ANN model generated was based on current data that did consider future economic influences. Thus, the final choice of spatially locating a particular level of facility was kept null to integrate the development authorities' decision.

Figure 13 shows the probable locations where future healthcare facilities were most preferred based on their correlation with informal settlements. The grid $(3 \times 3 \mathrm{~km})$ shows the basic unit of area (probable for dispensaries). Depending on the level of facility, 5.4 grids for one facility would denote the location of a tertiary-level facility (since the grid of influence is $49 \mathrm{~km}^{2}$ ). Similarly, 1.7 grids for one facility would denote the spatial location of a secondary-level facility (the grid of influence is $16 \mathrm{~km}^{2}$ ). For any primary-level facility, this would be a single grid.

The desirable range of probability was $0.6-0.999$ (constituting $68 \%$, i.e. $225.26 \mathrm{~km}^{2}$, of the area under PMC), which was represented in shades of blue in Figure 15. To supplement the validity of the predictive map, the model was run twice and a sample scenario is observed in Figure 15. It made use of the backpropagation algorithm to validate existing data and thus provided a reliable base. Figures 13 and 14 present the predictive statistics. 


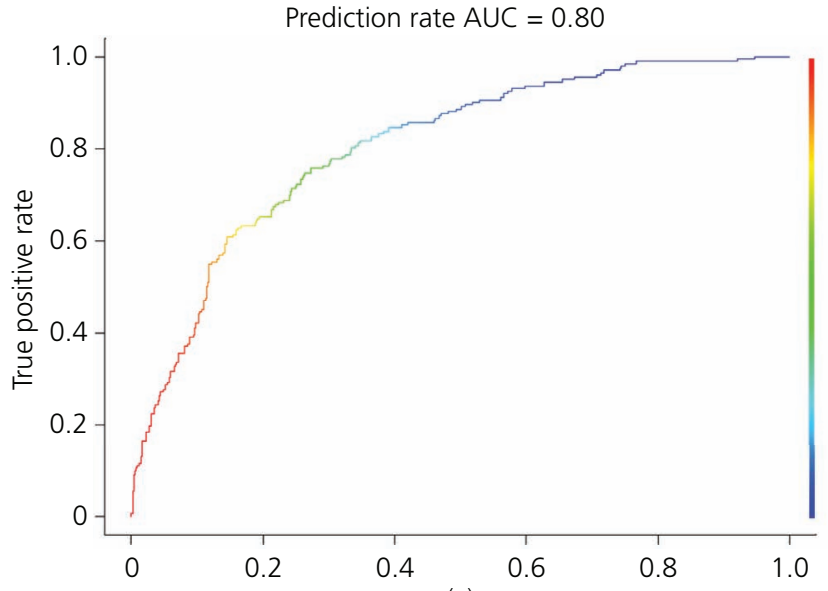

(a)

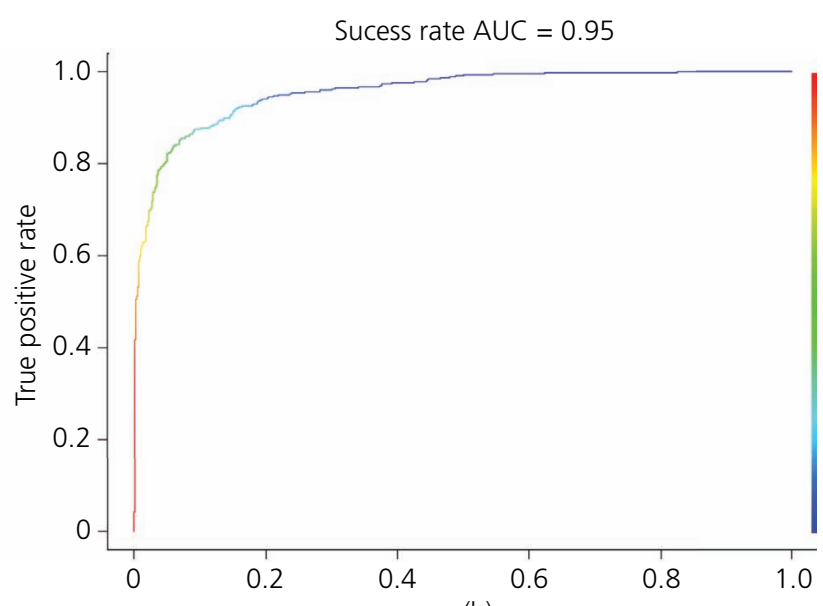

(b)

Figure 14. (a) Prediction and (b) success rates of the prediction model

The area under the curve (AUC) is a graphical tool that represents the probability of a data set. Thus, the prediction rate is $80 \%$ true for $95 \%$ of the distances recorded. This meant that as much as $80 \%$ of the data were converged onto $95 \%$ of raster limits of the study area despite changing certain parameters (as shown in Figure 15). The prediction and success rates together confirm the validity of the data as well as the high spatial correlation.

Thus, it was inferred that the spatial location of healthcare facilities was directly related to that of informal settlements. Thus, accessibility of any level of healthcare facility was as important as the affordability of that facility.

\subsection{ANN model scenario generation}

Once the ANN model had been developed, it was imperative to check its functionality if and when the criteria would change. This led to the generation of a sample scenario within the same limits of the study area while changing the criteria of locations of healthcare

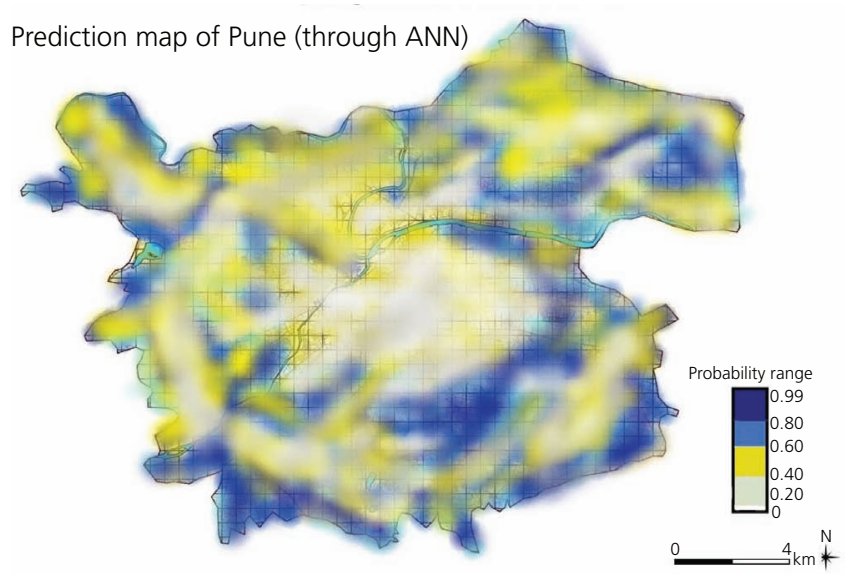

Figure 15. ANN modelling sample scenario facilities. Figure 15 shows the change observed in the developed model after changed criteria had been applied. For this sample scenario, the areas with the darkest shades of blue in Figure 13 were considered to be served with a newly developed secondary-level facility. After this, the predictive model program code was run once again and the new generated map was formulated. It should be noted here that the highly/moderately preferred regions for development of healthcare services, as identified by the $\mathrm{NN}$, are the regions that are currently unserved or those that do not have any facility within the threshold distance from an informal settlement.

On comparing Figures 13 and 15 spatially and statistically in the RStudio software program, it was analysed that the unserved areas in the developed model reduced drastically from $68 \%$ $\left(225.27 \mathrm{~km}^{2}\right.$ area $)$ to $43 \%\left(142.45 \mathrm{~km}^{2}\right.$ area $)$ in the sample scenario where all previous highest-priority (i.e. highestprobability) areas were served with a healthcare facility. Also, the least (and less) priority (or well-served) areas increased from 32\% $\left(106 \mathrm{~km}^{2}\right.$ area $)$ to $57 \%\left(188.82 \mathrm{~km}^{2}\right.$ area $)$ in the sample scenario. Thus, areas with 0.4 or less probability in Figure 13 became the most preferred with 0.8 probability in Figure 15 . Collectively considered, it showed that more people from informal settlements could have access to healthcare infrastructures. The sample scenario added seven secondary-level facilities to the existing roster and analysed their impact through the raster map generated in the RStudio software program. Table 3 provides the detailed changes in the predicted areas of priority.

For future studies, it is advisable for tertiary-level facilities to be located within a $500 \mathrm{~m}$ range from access roads to facilitate the emergency services of that facility. Preferably, locating more dispensaries in the study area should be given priority due to their limited existing number. Locating healthcare facilities in the newer developed wards and areas should be given priority to increase area under service. The growth of informal settlements should be monitored to integrate them while planning for new 
Table 3. Change in predicted priority areas $\left(\mathrm{km}^{2}\right)$

\begin{tabular}{|c|c|c|c|c|c|c|}
\hline Experiment & $\begin{array}{l}\text { Predicted locations of healthcare } \\
\text { facilities }\end{array}$ & $\begin{array}{c}\text { Least } \\
\text { preferred }\end{array}$ & $\begin{array}{l}\text { Less } \\
\text { preferred }\end{array}$ & $\begin{array}{l}\text { Moderately } \\
\text { preferred }\end{array}$ & $\begin{array}{l}\text { Highly } \\
\text { preferred }\end{array}$ & Total \\
\hline \multirow[t]{2}{*}{1} & Model developed & 72.87 & 33.13 & 109.32 & 115.94 & 331.26 \\
\hline & Area: \% & 22 & 10 & 33 & 35 & 100 \\
\hline \multirow[t]{2}{*}{2} & Sample scenario & 115.93 & 72.88 & 49.69 & 92.76 & 331.26 \\
\hline & Area: \% & 35 & 22 & 15 & 28 & 100 \\
\hline
\end{tabular}

healthcare facility locations. Addition of parameters such as income, age group and gender data could be included in the ANN model code to expand further the functionality of the model. This model code could be applied as it is for other similar cities in India to help aid development authorities formulate development plans. Spreading awareness of current new technologies through workshops for government authorities could help bridge the knowledge gap. Providing development officials with state-of-theart technical equipment may also help in creating a more efficient system for databases to enable analyses when required.

\section{Conclusion}

Healthcare infrastructure today has become one of the major factors in deciding the growth and development of an urban area. This research acts as a bridge to connect the lowest strata of society with basic healthcare needs. Previously, the relation between a type of healthcare facility and its distance from informal settlements was unknown. Healthcare facility distribution was not studied in conjunction with informal settlements due to numerous affecting criteria such as proximity, economic status of the settlers and income levels. This research helped establish a clear relation between the proximity and nature of facility. It also brought to light the existing clustered nature of facilities and its effect during an epidemic. Furthermore, the predicted model allowed for the final decision of placing tertiary, secondary and primary facilities to be made by planning authorities. This provides authorities the freedom to add further criteria to the predictive model.

With current Indian government policies reserving higher infrastructure budgets for the healthcare industry, it is imperative to optimise the spatial and demographic aspects and maximise benefits for all. Future work for such research could include the socio-economic aspect of the informal settlers, making policies even more citizen friendly.

\section{REFERENCES}

Aarthi A and Gnanappazham L (2019) Comparison of urban growth modelling using deep belief and neural network based cellular automata model - a case study of Chennai Metropolitan area, Tamil Nadu, India. Journal of Geographic Information System 11(1): 1-16, https://doi.org/10.4236/jgis.2019.111001.

AlThuwaynee O (2017) How to Easily Use ANN for Prediction Mapping Using GIS Data? Udemy, San Francisco, CA, USA. See https://www. udemy.com/course/how-to-use-ann-for-prediction-mapping-using-gisdata/ (accessed 20/11/2019).

APHA (American Public Health Association) (2014) What Is Public Health? APHA, Washington, DC, USA. See https://www.apha.org/ what-is-public-health (accessed 15/04/2020)
Brown JS, Holmes JH, Shah K, Hall K and Lazarus R (2010) Distributed health data networks: a practical and preferred approach to multiinstitutional evaluations of comparative effectiveness, safety, and quality of care. Medical Care 48(6): S45-S51, https://doi.org/10.1097/ MLR.0b013e3181d9919f.

Ciaburro G and Venkateswaran B (2017) Neural Networks with R: Smart Models Using CNN, RNN, Deep Learning, and Artificial Intelligence Principles, 1st edn. Packt Publishing, Birmingham, UK.

Gumber A (2002) Health Insurance for the Informal Sector: Problems and Prospects. Indian Council for Research on International Economic Relations, New Delhi, India.

Hesseldal L and Kayser L (2016) Healthcare innovation - the epital: a living lab in the intersection between the informal and formal structures. Qualitative Sociology Review 12(2): 60-80, https://doi.org/ 10.18778/1733-8077.12.2.04

Kumar S, Kumar S and Gupta B (2018) Urban health: needs urgent attention. Indian Journal of Public Health 62(3): 214-217, https://doi. org/10.4103/ijph.IJPH 9018.

Mashal (Maharashtra Social Housing and Action League) (2010) Housing Study for Pune Municipal Corporation. Pune Municipal Corporation, Pune, India.

Ministry of Urban Development (2015) Government of India. Urban and Regional Development Planning and Framework Implementation. Ministry of Urban Development, New Delhi, India. See https://mohua. gov.in/ (accessed 06/06/2020).

MoHFW (Ministry of Health and Family Welfare) (2013) National Urban Health Mission - Framework for Implementation. National Health Mission, New Delhi, India.

NITI Aayog (2019) Health System for a New India: Building Blocks Potential Pathways to Reform. NITI Aayog, New Delhi, India.

Noack S, Knobloch A, Etzold SH, Barth A and Kallmeier E (2014) Spatial predictive mapping using artificial neural networks. International Archives of the Photogrammetry, Remote Sensing and Spatial Information Sciences XL-2: 79-86, https://doi.org/10.5194/ isprsarchives-XL-2-79-2014.

OECD (Organisation for Economic Co-operation and Development) (2003) Glossary of Statistical Terms: Informal Sector - ILO. OECD, Paris, France. See https://stats.oecd.org/glossary/detail.asp?ID=1350 (accessed 11/04/2020).

Orgi (Office of the Registrar General and Census Commissioner, India) (2011) Census of India. Orgi, New Delhi, India. See https://censusindia.gov. in/2011-common/censusdata2011.html (accessed 01/06/2020).

PMC (Pune Municipal Corporation) (2015) City Development Plan for Pune - 2041. PMC, Pune, India. See https://www.pmc.gov.in/en/draftcity-development-plan-pune-city-2041-vol-2 (accessed 28/05/2020).

Rao M, Ramachandra SS, Bandyopadhyay S et al. (2011) Addressing healthcare needs of people living below the poverty line: a rapid assessment of the Andhra Pradesh Health Insurance Scheme. National Medical Journal of India 24(6): 335-341.

Revelu A (2020) Assessing urban critical infrastructure using online GIS and ANN: an empirical study of Bucharest City (Romania). In Science and Technologies for Smart Cities: 5th EAI International Summit, SmartCity360, Braga, Portugal, December 4-6, 2019, Proceedings (Santos H, Pereira GB, Budde M, Lopes SF and Nikolic P (eds)). Springer, Cham, Switzerland, pp. 153-161. 
Smart Infrastructure and Construction

Volume 175 Issue 3
Evaluating healthcare access in informal settlements using satellites and neural

networks

Pal and Petkar
Rockefeller Foundation (2013) Health Vulnerabilities of Informal Workers. Rockefeller Foundation, New York, NY, USA. See https:// www.rockefellerfoundation.org/wp-content/uploads/HealthVulnerabilities-of-Informal-Workers.pdf (accessed 24/11/2020).

Škrabánek P and Martínková N (2021) Algorithm 1017: fuzzyreg: an R package for fitting fuzzy regression models. ACM Transactions on Mathematical Software 47(3): article 29, https://doi.org/10.1145/3451389.
WHO (World Health Organization) (2014) Public Health Services. WHO, Geneva, Switzerland. See https:/www.euro.who.int/en/ health-topics/Health-systems/public-health-services (accessed 15/04/ 2020).

WSA (Wilbur Smith Associates) and IL\&FS (Infrastructure Leasing \& Financial Services Limited) (2008) Comprehensive Mobility Plan for Pune City. Pune Municipal Corporation, Pune, India.

\section{How can you contribute?}

To discuss this paper, please email up to 500 words to the editor at journals@ice.org.uk. Your contribution will be forwarded to the author(s) for a reply and, if considered appropriate by the editorial board, it will be published as discussion in a future issue of the journal.

Proceedings journals rely entirely on contributions from the civil engineering profession (and allied disciplines). Information about how to submit your paper online is available at www.icevirtuallibrary.com/page/authors, where you will also find detailed author guidelines. 